\title{
Effect of Dew Point and Gas Flow Rate on the Surface Oxidation of Advanced High Strength Steels
}

\author{
II-Ryoung SOHN, ${ }^{1) *}$ Jong-Sang $\mathrm{KIM}^{1)}$ and Seetharaman SRIDHAR ${ }^{2)}$ \\ 1) Technical Research Laboratories, POSCO, Gwangyang, 545-875 Korea. \\ 2) Formerly Dept. of Material Science Engineering, Carnegie Mellon University. Now at Advanced Steel Research Centre, \\ WMG, The University of Warwick, Coventry CV4 7AL, UK.
}

(Received on March 19, 2015; accepted on May 7, 2015)

\begin{abstract}
The chemical and morphological features of oxides, at or near a steel surface, greatly influence the formation of the inhibition layer, critical for controlling the quality of the coating during immersion into the $\mathrm{Zn}$ bath. The oxides influence the wettability and the final composition of the Fe-Zn alloy coating. In this study, oxidation behaviors of Advanced High Strength Steels (AHSS) are studied during annealing in a $\mathrm{H}_{2}-5 \% \mathrm{~N}_{2}$ atmosphere with controlled dew-points $\left(0\right.$ to $\left.-40^{\circ} \mathrm{C}\right)$ and gas flow rates (5 to $100 \mathrm{l} / \mathrm{min}$.). Compact external oxides, with a high $\mathrm{SiO}_{2}, \mathrm{Al}_{2} \mathrm{O}_{3}$ ratio, were found to form on the steel surface when the dew point was low and/or the gas-flow rates high. As dew points were increased and gas-flow rates decreased the surface oxides became less continuous and the presence of internal oxides became substantial. The influence of gas-flow rate cannot be attributed solely to the gas phase transport of oxidants to the metal surface and it is suggested that the equilibration state of the gas and consequent amount of molecular oxygen present near the surface needs to be considered.
\end{abstract}

KEY WORDS: oxidation; non-equilibrium state; oxide; steel; high strength; annealing.

\section{Introduction}

Automotive industries strive to reduce the weight of car bodies in order to meet the regulation of $\mathrm{CO}_{2}$ emission per mileage. In addition the car bodies need to be crash worthy to meet passenger safety regulations. Advanced High Strength Steels (AHSS) have been developed to meet these requirements. Transformation Induced Plasticity (TRIP) and Dual Phase (DP) steels have increased in application in automotive parts but may be substituted by steels of even higher strength grades. ${ }^{1)}$ Furthermore, more ultra-high strength components with strength over $1 \mathrm{GPa}$ are expected to be applied in car bodies in the near future. ${ }^{1,2)}$

One challenge to manufacturing automotive steel sheets is the ability to eliminate the imperfection in the $\mathrm{Zn}$ coating on the steel surface caused by surface oxides formed during the annealing process. The oxides interrupt the formation of the inhibition layer which forms between the molten $\mathrm{Zn}$ and steel surface. ${ }^{3,4)}$ The inhibition layer is critical for controlling the coating thickness and if it is not formed uniformly could result in un-coated areas (so called bare spots) and irregularities in the $\mathrm{Zn}$ coating.

Most of high strength steels for automotive application contain high levels of $\mathrm{Al}, \mathrm{Si}$ and $\mathrm{Mn}$ and sometimes $\mathrm{B}$ for strength and toughness. Most of these additional elements are easily oxidized and form strong oxides on the steel surface that cause the aforementioned defects on the coating.

\footnotetext{
* Corresponding author: E-mail: irsohn@posco.com

DOI: http://dx.doi.org/10.2355/isijinternational.ISIJINT-2015-158
}

There have been many studies on the oxidation behaviors during annealing conditions. ${ }^{3-11)}$ To identify ways to reduce surface oxides, studies were carried out in various annealing conditions; such as the influence of oxygen partial pressure or $\mathrm{H}_{2} / \mathrm{N}_{2}$ ratio in atmosphere, $\mathrm{Si} / \mathrm{Mn}$ ratio or trace elements in steel compositions etc. Most of these investigations were focused on the reaction of metals with oxygen in atmospheres that were assumed to be under (or near) thermodynamic equilibrium conditions wherein the oxygen partial pressure in atmosphere was determined by gas phase equilibrium. However, Kwon et al. ${ }^{12)}$ proposed that oxidation of steels during the annealing process could take place under conditions wherein the gas phase was not in equilibrium. Grabke and coworkers have reported oxide-carbide conversion behavior under non-equilibrium conditions in $\mathrm{H}_{2}-\mathrm{H}_{2} \mathrm{O}-\mathrm{CH}_{4}-\mathrm{CO}$ atmospheres. ${ }^{13)}$ Non-equilibrium conditions are of importance industrially since, during processing, oxidation occurs within relatively short times (heating and soaking time is limited to approximately $10 \mathrm{~min}$.) in mixed gas atmospheres supplied at room temperature into the annealing furnace.

In this study, oxidation during annealing of $\mathrm{Si}-\mathrm{Mn}$ steels under a $\mathrm{N}_{2}-\mathrm{H}_{2}$ gas are investigated under non-equilibrium conditions. The atmosphere consisted of $\mathrm{N}_{2}$ and $\mathrm{H}_{2}$ with minor oxidizing elements such as $\mathrm{O}_{2}$ and $\mathrm{H}_{2} \mathrm{O}$. In the conventional studies, oxygen partial pressure is determined (or assumed to be determined) by the equilibrium state of $\mathrm{H}_{2}+\mathrm{O}_{2}=\mathrm{H}_{2} \mathrm{O}$ and the oxygen partial pressure is determined through thermodynamics from the initial $\mathrm{H}_{2} \mathrm{O}$ quantity, temperature, and $\mathrm{H}_{2} / \mathrm{O}_{2}$ ratio. In this work, however, gas 
flow rate is taken as an important factor which influences whether or not thermodynamic equilibrium is reached in the atmosphere. Oxidation is studied by using various flow rates of atmospheric gas. The $\mathrm{H}_{2} \mathrm{O}$ level is changed by controlling the dew point (D.P.) to investigate the distinct effects of flow rate and $\mathrm{H}_{2} \mathrm{O}$ level in the atmosphere on the resulting oxidation products.

\section{Experimental}

The study is focused on samples from commercially produced steel with composition of $0.09 \mathrm{C}-1.7 \mathrm{Mn}-1.22 \mathrm{Si}-$ 0.02Sb-0.044Al-0.0004B (all units in wt\%) with some impurities. The specimens were machined to $120 \times 200 \mathrm{~mm}$ coupons of $1.5 \mathrm{~mm}$ thickness from industrial cold rolled full hardened strips. Just before the annealing tests, the grease on the specimens was removed by alkaline cleaning using a $\mathrm{NaOH}$ solution. The annealing oxidation was carried out in a laboratory scale Iwatani ${ }^{\circledR}$ hot-dip simulator. The specimens are annealed under the heat cycle in Table $\mathbf{1 .}$

The atmospheric gas was composed of $\mathrm{N}_{2}-5 \mathrm{vol} \% \mathrm{H}_{2}$ and the free $\mathrm{O}_{2}$ was measured with a doped $\mathrm{Zr}$ sensor and determined to be less than 1 volume ppm in the gas. It is equivalent to be less than $10^{-6}$ atm. The water vapor contents in the gas are monitored through a dew point monitor. The experimental dew points, examined in this study were $-40^{\circ} \mathrm{C},-20^{\circ} \mathrm{C}$, and $0^{\circ} \mathrm{C}$. Gas flow rate was controlled at 3 distinct levels of $5 \mathrm{l} / \mathrm{min}$., $30 \mathrm{\ell} / \mathrm{min}$., and $100 \mathrm{\ell} / \mathrm{min}$. The reaction chamber consisted of a quartz tube with inner diameter of $150 \mathrm{~mm}$ and its length is $1200 \mathrm{~mm}$. The average linear gas flow speed in the reaction chamber was calculated as $28.3 \mathrm{~cm} / \mathrm{min}$., $169.8 \mathrm{~cm} / \mathrm{min}$., and $565.8 \mathrm{~cm} / \mathrm{min}$. for the three respective gas flow rates. Thermodynamic calculations were carried out using the commercial package FactSage 6.4. ${ }^{14)}$ Table 2 shows the partial pressures of $\mathrm{O}_{2}$ at $800^{\circ} \mathrm{C}$ in the test atmospheres assuming that thermodynamic equilibrium was established. ${ }^{9)}$ The computed equilibrium partial pressures of $\mathrm{O}_{2}$ in equilibrium with the $\mathrm{Al}, \mathrm{Si}$ and $\mathrm{Mn}$ dissolved in the alloy and their respective oxides, $\mathrm{Al}_{2} \mathrm{O}_{3}, \mathrm{SiO}_{2}$ and $\mathrm{MnO}$ were calculated to be between $10^{-30}-10^{-44}$ atm at $800^{\circ} \mathrm{C}$. In the case of the $\mathrm{Fe} / \mathrm{FeO}$ equilibrium the oxygen partial pressure was calculated to be $10^{-19}$ atm. Under the atmospheric conditions in Table 2, the oxides of Al, Si and Mn can therefore be considered to be thermodynamically stable since the experimental equilibrium oxygen partial pressures are higher than the ones corresponding to the

Table 2. Partial pressure of $\mathrm{H}_{2} \mathrm{O}$ and $\mathrm{O}_{2}$ in the atmosphere at $800^{\circ} \mathrm{C}$ with variation of dew point.

\begin{tabular}{cccc}
\hline Dew point $\left({ }^{\circ} \mathrm{C}\right)$ & 0 & -20 & -40 \\
\hline $\begin{array}{c}\mathrm{Po}_{2} \text { in } \mathrm{N}_{2}-5 \% \mathrm{H}_{2} \\
\text { at } 800^{\circ} \mathrm{C}\end{array}$ & $2.57 \times 10^{-20}$ & $7.3 \times 10^{-22}$ & $1.16 \times 10^{-23}$ \\
\hline
\end{tabular}

metal/oxide equilibrium. Fe-oxides on the other hand are not thermodynamically stable unless the form as complex oxides with other elements or as $\mathrm{FeO}$ in solution with other oxides.

After the annealing experiments, the specimens were characterized by using a Field Emission Scanning Electron Microscope (FE SEM, AURIGA FIB-SEM, ZEISS) and a $200 \mathrm{KV}$ Scanning Transmission Electron Microscope (STEM, JEM 2100F FE TEM, JEOL). Cross sections of the samples were prepared by focused ion beam (FIB) and inspected by STEM. Spot analysis was carried out through STEM EDS with a probe size of less than $1 \mathrm{~nm}$. Spot Anayses on the sample carried out 3 places to evaluate the range of elements in the oxides. These element range would considered as typical value from random survey.

Elemental profiles on the sample's surface were measured by using Glow Discharge Optical Emission Spectrometry (GDOES). The measured spot size of GDOES was $4 \mathrm{~mm}$ diameter. The surface peaks of the profiles in GDOES show the amounts of elements in surface oxides. The peak are integrated to evaluate the amount of an element. ${ }^{15)}$ The area of this surface peak was integrated and this value was used as relative amounts of elements in the surface oxides.

\section{Results and Discussions}

\subsection{Oxidation Behaviors with Various DP and Flow Rate}

Figure 1 shows STEM images of cross sections of the samples after annealing tests at various dew points and gas flow rates in the $\mathrm{N}_{2}-5 \% \mathrm{H}_{2}$ atmosphere. In all the images the top surfaces of the samples are covered with a white layer which is an artificial Pt coating which is applied to protect the samples surface during the preparation for TEM samples. Oxides in the samples appear as dark regions in the image. The image (f) in Fig. 1 is an exception. In this case, white and dark is reversed because it was obtained as a dark field image from TEM. In the case of dew point of $0^{\circ} \mathrm{C}$, internal oxides were developed in all the samples regardless of gas flow rates. The depth of internal oxides seems to increase with the increase in gas flow rates at $0^{\circ} \mathrm{C}$ dew point. With the decrease of dew point the development of internal oxides is influenced by gas flow rates. In the relatively higher flow rate, little internal oxides are observed in the sample's cross sections such as (f), (h) and (i) in Fig. 1. The internal-external oxidation behaviors shows clear trend with the variation of dew point and gas flow rate. It is well known that, in the absence of a continuous external scale, higher dew points cause internal oxidations as a result of increased dissolved oxygen concentration at the surface. ${ }^{16}$ ) In agreement with other reported results, $\left.{ }^{6}\right)$ it was observed that the internal oxidation developed at dew points of $0^{\circ} \mathrm{C}$ or higher in this study under $100 \mathrm{l} / \mathrm{min}$ flow rate. What is noteworthy however is that the appearance of internal

Table 1. Annealing heat cycle.

\begin{tabular}{ccccccc}
\hline $\begin{array}{c}\text { Heating rate } \\
\left({ }^{\circ} \mathrm{C} / \mathrm{s}\right)\end{array}$ & $\begin{array}{c}\text { Soaking temp. } \\
\left({ }^{\circ} \mathrm{C}\right)\end{array}$ & $\begin{array}{c}\text { Soaking time } \\
(\mathrm{s})\end{array}$ & $\begin{array}{c}\text { Cooling rate } \\
\left({ }^{\circ} \mathrm{C} / \mathrm{s}\right)\end{array}$ & $\begin{array}{c}\text { Over-aging temp. } \\
\left({ }^{\circ} \mathrm{C}\right)\end{array}$ & $\begin{array}{c}\text { Over-aging time } \\
(\mathrm{s})\end{array}$ & $\begin{array}{c}\text { Cooling rate } \\
\left({ }^{\circ} \mathrm{C} / \mathrm{s}\right)\end{array}$ \\
\hline 2.2 & 800 & 61 & -35 & 500 & 200 \\
\hline
\end{tabular}


oxides shifted to lower dew points when the gas flow rate was decreased.

The oxide micro structures were inspected by STEM and EDS. Figure 2 shows a surface and a cross section image of the sample annealed at D.P $0^{\circ} \mathrm{C}$ and gas flow rate $100 \mathrm{l} / \mathrm{min}$. (same sample in Fig. 1(c)). Oxides coverage on the sample surface can be found to be non-continuous with regards to surface coverage and in some cases no visible oxides were found on the surface. Furthermore, oxides form as mixed morphology consisting of very thin plate oxides and nodule type oxides of less than $100 \mathrm{~nm}$ thickness. The different type of oxides are indicated in Fig. 2 The morphologies of oxides are indicated in Fig. 2(b). This is support of the observed dependence of internal oxide depth on gas flow rate and dew-point. Both internal oxides and external oxides were found to consist, primarily of $\mathrm{Si}$ and $\mathrm{Mn}$ oxides. The $\mathrm{Si} / \mathrm{Mn}$ ratios in the oxides were surveyed in 3 places on the sample besides the ones indicated in Fig. 2 (which is shown as an example). The $\mathrm{Si} / \mathrm{Mn}$ ratio in the external oxides were found to be $0.45-0.83$. Internal oxides show higher $\mathrm{Si} / \mathrm{Mn}$ and some points in the internal oxides consisted only $\mathrm{Si}$ without Mn. Internal oxides mainly follow grain boundaries and are composed of $\mathrm{Si}-\mathrm{Mn}$ oxides with a $\mathrm{Si} / \mathrm{Mn}$ ratio ranging from 1.75 in those of point 7 in Fig. 2(b) and Table 3 but in other locations were found to be as high as 16.6. Fine oxide particles were formed in grain interior as shown in point 6 in the same Figure.

It is noteworthy that $\mathrm{P}$ was found to be concentrated in the external oxides. Points 4 and 5 in Fig. 2(b) show that $\mathrm{P}$ contents in nodule like oxides are 3.3-8.0 at\%. Figure 3(a) shows GDOES profiles for the surface enrichments of $\mathrm{Si}$, $\mathrm{Mn}, \mathrm{P}$ and $\mathrm{O}$ on the sample in $\mathrm{DP} 0^{\circ} \mathrm{C}$ when the gas flow

Table 3. Spot analyses by EDS on (b) in Fig. 2 (unit: atomic\%).

\begin{tabular}{cccccccc}
\hline point & $\mathrm{O}$ & $\mathrm{Al}$ & $\mathrm{Si}$ & $\mathrm{Mn}$ & $\mathrm{Fe}$ & $\mathrm{P}$ & $\mathrm{Si} / \mathrm{Mn}$ \\
\hline 1 & 42.5 & - & 26.1 & 31.4 & - & - & 0.83 \\
2 & 38.1 & - & 24.6 & 37.3 & - & - & 0.66 \\
3 & 41.1 & - & 21.2 & 31.2 & 6.5 & - & 0.68 \\
4 & 42.3 & - & 17.4 & 32.3 & - & 8.0 & 0.54 \\
5 & 43.3 & - & 16.6 & 36.8 & - & 3.3 & 0.45 \\
6 & 19.7 & - & 10.2 & - & 70.1 & - & - \\
7 & 57.4 & - & 27.1 & 15.5 & - & - & 1.75 \\
\hline
\end{tabular}

$5 \ell / \mathrm{min}$

$0^{\circ} \mathrm{C}$

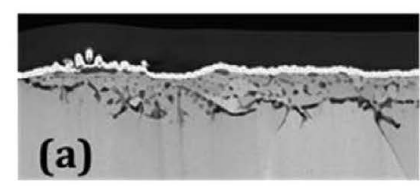

$-20^{\circ} \mathrm{C}$

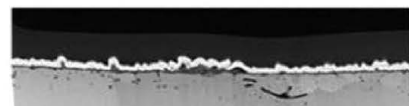

(d)

$-40^{\circ} \mathrm{C}$

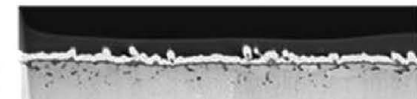

(g)
$30 \ell / \mathrm{min}$.
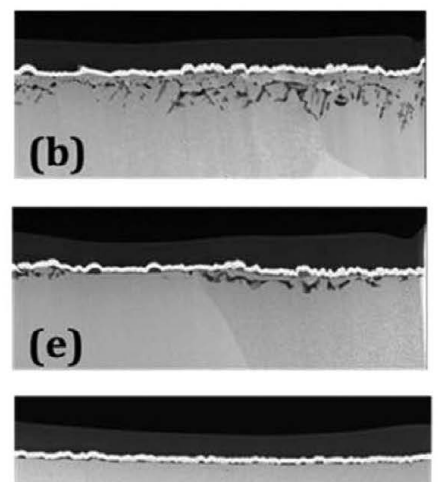

(h)
$100 \ell / \mathrm{min}$.
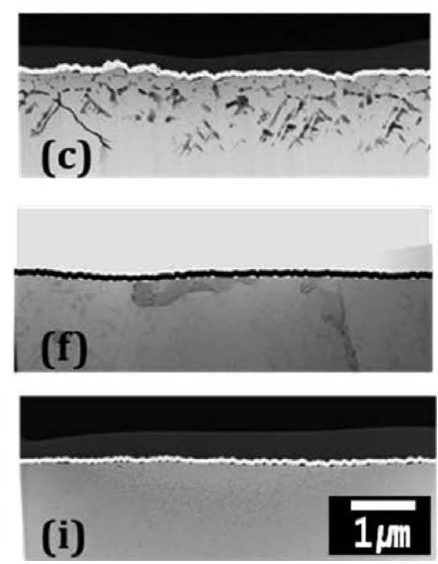

Fig. 1. Cross sections of annealed samples in $\mathrm{N}_{2}-5 \% \mathrm{H}_{2}$ at $800^{\circ} \mathrm{C}$. Dewpoint is $0 \sim-40^{\circ} \mathrm{C}$ and gas flow rate $5-100 \ell / \mathrm{min}$. (STEM images).

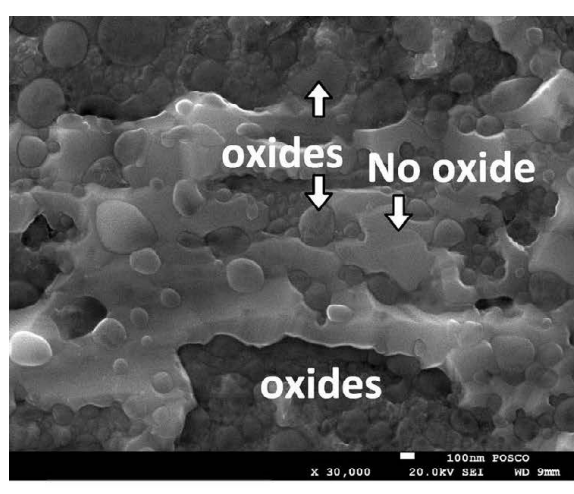

$-400 \mathrm{~nm}$

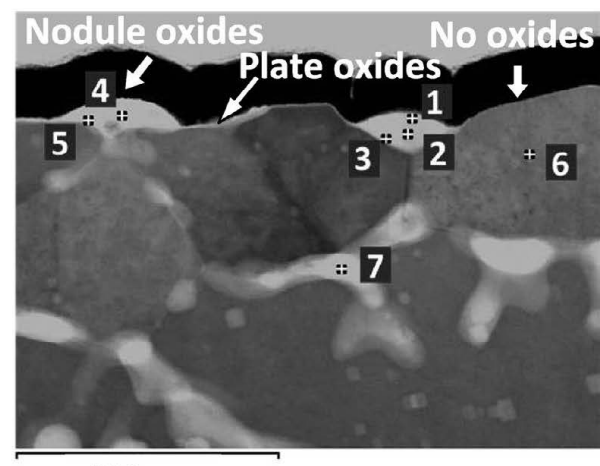

$400 \mathrm{~nm}$

(a)

(b)

Fig. 2. Surface and cross section image of a sample annealed at $800^{\circ} \mathrm{C}$ in $\mathrm{H}_{2}-5 \% \mathrm{H}_{2}$ of D.P $0{ }^{\circ} \mathrm{C}$. Gas flow rate is 100 $\ell /$ min. (a) a surface image by FE-SEM, (b) a cross section image by STEM and point number $1-7$ indicates EDS point analysis spots. 
rate was $100 \ell / \mathrm{min}$. Figure 3(b) shows the GDOES profiles of $\mathrm{P}$ on the surface of the samples exposed to DP's of 0 , -20 and $-40^{\circ} \mathrm{C}$. (same sample in Figs. 1(c), 1(f) and 1(i)). A Sharp concentration of $\mathrm{P}$ on the top surface of the sample is significantly increased at DP $0^{\circ} \mathrm{C}$ in comparison to DP $-20,-40^{\circ} \mathrm{C}$. The $\mathrm{P}$ profiles almost overlapped in DP -20 and $-40^{\circ} \mathrm{C}$ in Fig. 3(b).

GDOES analyses are carried out at 3 points on the samples and each peak's area is calculated by integration. Based on the area of peaks, P content is calculated out of total major elements. From the GDOES peaks, it is estimated that $\mathrm{P}$ is $3.8-8.7 \mathrm{wt} \%$ in the summation of 4 major metallic elements ( $\mathrm{Si}, \mathrm{Mn}, \mathrm{P}$ and $\mathrm{Al}$ ) in the surface oxide layer on the sample tested in DP $0^{\circ} \mathrm{C}$. On the same calculation, $\mathrm{P}$ is $0.2-0.5 \mathrm{wt} \%$ in the surface oxides in the samples exposed to DP's of -20 and $-40^{\circ} \mathrm{C}$. The $\mathrm{P}$ concentration is similarly higher at DP $0^{\circ} \mathrm{C}$ in other flow rates of 5 and 30 $\ell /$ min. Under equilibrium, the partial $\mathrm{O}_{2}$ pressure of $\mathrm{P}_{4} \mathrm{O}_{10}$ is $3.3 \times 10^{-20}$ atm based on thermodynamic data from FactSage 6.4. ${ }^{14)}$ This is significantly higher than the aforementioned equilibrium partial pressure of oxygen for the other alloy- ing elements, $\mathrm{Si}, \mathrm{Mn}$ and $\mathrm{Al}$. As the oxygen concentration decreased, at lower dew points, oxidation of phosphorus does not occur. It would seem reasonable that $\mathrm{P}$ oxides would form after the more reactive elements such as $\mathrm{Si}$, $\mathrm{Mn}$ and $\mathrm{Al}$ are consumed. It is likely that $\mathrm{P}$ is not oxidized internally because the internal equilibrium oxygen pressure (set by $\mathrm{Mn}$ and/or Si oxides) is below that required to oxidize the dissolved P. P would instead diffuse to the surface and react at the surface once the soluble $\mathrm{Si}, \mathrm{Mn}$ and $\mathrm{B}$, near the surface are depleted. All the samples tested at DP $0^{\circ} \mathrm{C}$ show $\mathrm{P}$ concentrated on the surface in this study. It is also reported that $\mathrm{P}$ oxides are present in the surface oxide layer at DP $0{ }^{\circ} \mathrm{C}$, and it is not detected at $-30,-60{ }^{\circ} \mathrm{C}{ }^{11)}$ Thus, the cause for the $\mathrm{P}$ profile shown in Fig. 3 is likely external oxidation of $\mathrm{P}$, and the outward diffusion of $\mathrm{P}$ to replenish the depleted $\mathrm{P}$ in the underlying metal.

Figure 4 shows a surface and a cross section image of the sample annealed at $\mathrm{DP}-40^{\circ} \mathrm{C}$ when gas flow rate is decreased to $5 \mathrm{l} / \mathrm{min}$. (same sample in Fig. $1(\mathrm{~g})$ ). Table 4 shows EDS results on the points in Fig. 4. Oxides are formed throughout the whole surface regularly in comparison to

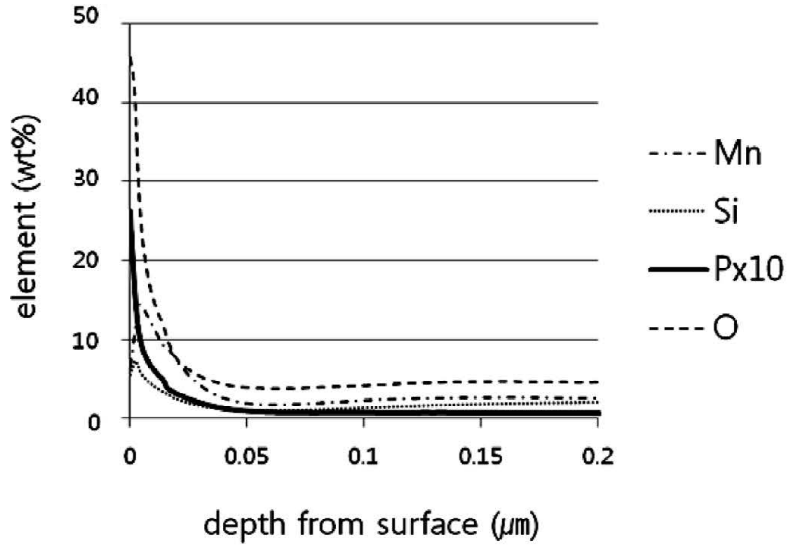

(a)

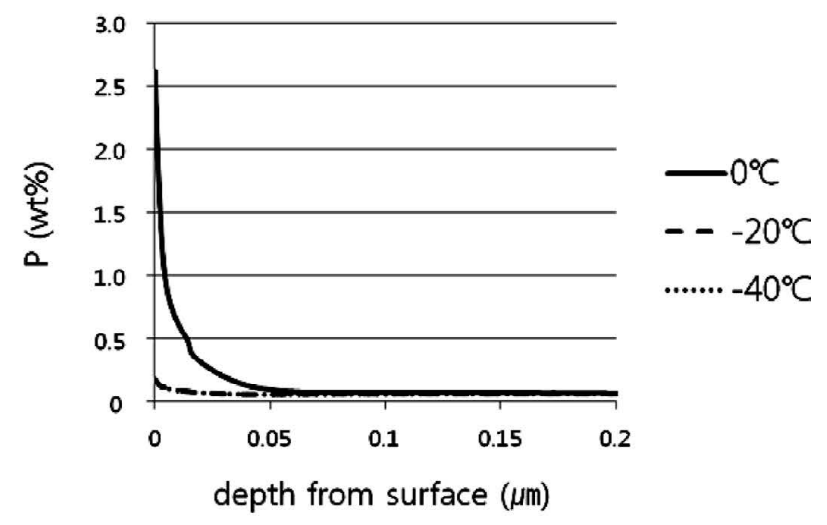

(b)

Fig. 3. GDOES P profiles in the samples annealed at $800^{\circ} \mathrm{C}$ in $\mathrm{N}_{2}-5 \% \mathrm{H}_{2}$ of DP $0 \sim-40^{\circ} \mathrm{C}$ with gas flow rate of $100 \ell / \mathrm{min}$.

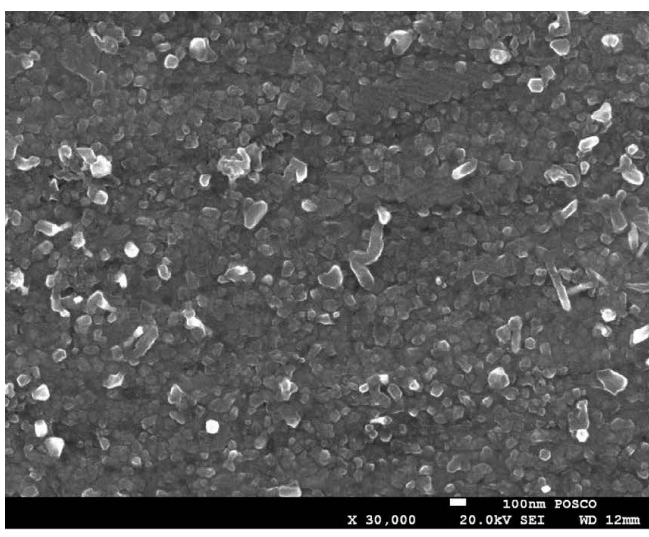

$400 \mathrm{~nm}$

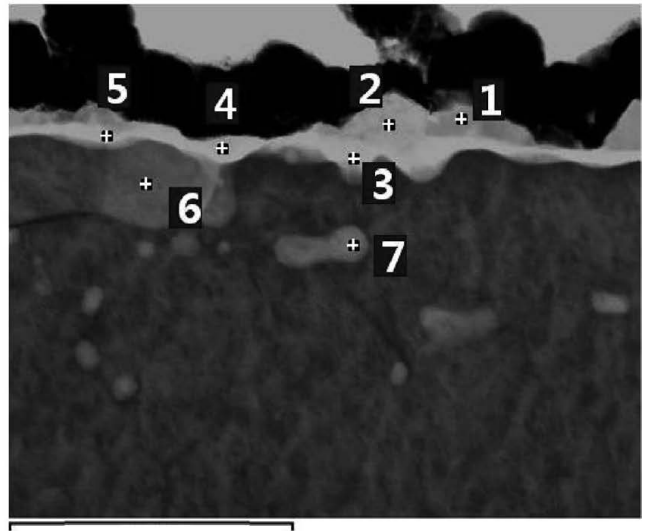

$400 \mathrm{~nm}$

(a)

(b)

Fig. 4. Surface and cross section image of a sample annealed at $800^{\circ} \mathrm{C}$ in $\mathrm{H}_{2}-5 \% \mathrm{H}_{2}$ of D.P $-40^{\circ} \mathrm{C}$. Gas flow rate is 5 $\ell / \mathrm{min}$. (a) a surface image by FE-SEM, (b) a cross section image by STEM and point number 1-8 indicates EDS point analysis spots. 
what was seen in Fig. 2. In the cross section it can be seen that that surface oxides form a stable continuous layer with a thickness of about $20 \mathrm{~nm}$ and nodules form with thickness of over $100 \mathrm{~nm}$. Point 4 in Fig. 4(b) is the EDS analysis spots on the continuous layer and $\mathrm{Si} / \mathrm{Mn}$ ratio is 0.69 .

The $\mathrm{Si} / \mathrm{Mn}$ ratio in continuous layers shows $0.2-3.3$ in the analysis in 3 places on the samples. Point 1, 2, 3, 5 in Fig. 4(b) are on the nodule oxides. Upper part of a nodule forms faceted shape and consist almost in pure Mn oxides as shown in point 1, 2 and lower part consist in $\mathrm{Si}-\mathrm{Mn}$ oxides which $\mathrm{Si} / \mathrm{Mn}$ ratio is 0.77 and 3.27 as shown in point 3 and 5 in Fig. 4 and Table 4. The nodules usually composed of higher $\mathrm{Mn}$ oxides in the top and higher $\mathrm{Si}$ in the bottom areas.

Point 5 is detected some elements of $\mathrm{Si}, \mathrm{Mn}$ and $\mathrm{Fe}$, however, point 3 shows on $\mathrm{Si}, \mathrm{Mn}$. Point 7 shows an internal oxides and it consist in $\mathrm{O}-\mathrm{Al}-\mathrm{Si}-\mathrm{Mn}-\mathrm{Fe}$. Si oxides combined with $\mathrm{Fe}$ oxides could result in the formation of Fayalite. While EDS analysis is to inaccurate to confirm its existence, the co existance of $\mathrm{Fe}$ and substantial amount of $\mathrm{Si}$ has been shown in literature to be the formation of Fayalite. $^{17)}$

However, it is not clear whether the Fe indeed exists as oxides or whether the signal comes from the background in the steel matrix. Al is not detected in the external oxides and it is included in the internal oxides as shown in point 7

Table 4. Spot analyses by EDS on (b) in Fig. 4 (unit: atomic\%).

\begin{tabular}{ccccccc}
\hline point & $\mathrm{O}$ & $\mathrm{Al}$ & $\mathrm{Si}$ & $\mathrm{Mn}$ & $\mathrm{Fe}$ & $\mathrm{Si} / \mathrm{Mn}$ \\
\hline 1 & 42.9 & - & - & 57.1 & - & - \\
2 & 38.4 & - & - & 58.7 & 2.93 & - \\
3 & 46.4 & - & 23.3 & 30.3 & - & 0.77 \\
4 & 40.4 & - & 24.4 & 35.2 & - & 0.69 \\
5 & 55.7 & - & 23.2 & 7.1 & 14.1 & 3.27 \\
6 & & - & - & - & 100 & - \\
7 & 33.3 & 2.1 & 15.1 & 4.6 & 45 & 3.28 \\
\hline
\end{tabular}

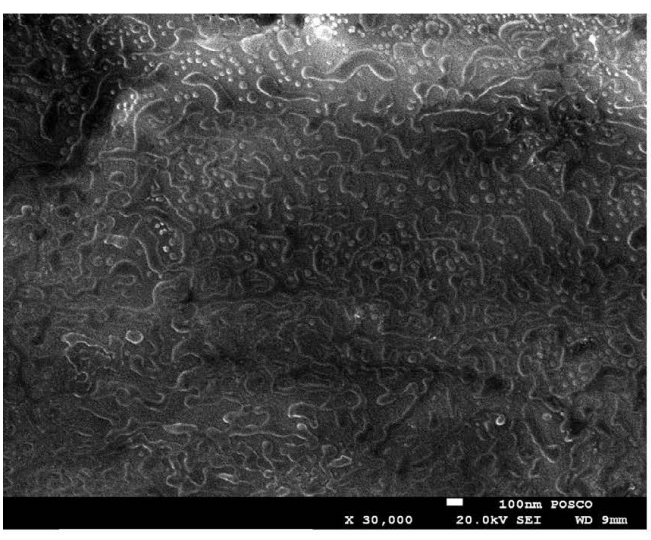

$-400 \mathrm{~nm}$ in Fig. 4 and Table 4.

Figure 5 shows a surface and a cross section image of the sample annealed at $\mathrm{DP}-40^{\circ} \mathrm{C}$ and gas flow rate $100 \mathrm{l} / \mathrm{min}$. (the sample shown in Fig. 1(i)). Oxide morphologies on the surface in Fig.5(a) have a liquid appearance with phases adhering on the surface irregularly. Internal oxides are not present and external oxides cover the whole surface and consist of nodular type oxides and thin flat oxides as shown in Fig. 5(b). The externally shaped nodular type oxides are analyzed by EDS in 3 places of the sample. The oxides are composed of $\mathrm{Si}$ oxide only or $\mathrm{Si}-\mathrm{Mn}$ oxides with $\mathrm{Si}$ / Mn ratio of 4.8-27.5. In the nodular oxides, the upper part seems to be constituted of Si oxide whereas the lower parts are composed of Si-Mn oxides. When considering the accuracy of the characterization methods used however it can not be excluded that the oxide is $\mathrm{SiO}_{2}$. Some other oxides consisting of $\mathrm{Fe}-\mathrm{Si}-\mathrm{Mn}$ can also be observed. Si ratio in these oxides are higher in comparison to the sample annealed in DP $0^{\circ} \mathrm{C}$, listed in Fig. 2 and Table 3. About 2.3-5.8 at $\% \mathrm{Al}$ was detected in the lower part of the nodular oxides in the observed sample. This value is quite high when considering the low contents of $\mathrm{Al}$ in the steel matrix. The $\mathrm{Al}$ in the steel matrix was measured to be 0.09 at $\%$. The Al concentration on the surface oxides is consistently present in the samples in which little internal oxides were observed in Figs. 1(f), 1(h), and 1(I). In contrast, there was little Al detected in the external oxides in the case of DP $0{ }^{\circ} \mathrm{C}$.

As noted, a small amount of $\mathrm{Fe}$ was found in the external oxides. It is likely that Fe would not form as separate Fe oxides but as a complex oxide or as $\mathrm{FeO}$ dissolved in $\mathrm{MnO}$ due to the relatively low stability of Fe-oxides. It was not clearly observed that the change of gas flow rate had any influence on the amount of Fe oxides. When flow rate is increased, it is possible that the $\mathrm{Po}_{2}$ increased because non-equilibrated $\mathrm{O}_{2}$ in initial supply gas could react with $\mathrm{Fe}$ on the surface and form $\mathrm{Fe}$ oxides. Kwon et al. ${ }^{12)}$ reported that only $\mathrm{Fe}_{3} \mathrm{O}_{4}$ formed on the surface of TRIP steels when gas flow exceeds $150 \mathrm{~cm} / \mathrm{min}$. and DP is higher than $-30^{\circ} \mathrm{C}$ when annealing in a $\mathrm{Ar}-5 \% \mathrm{H}_{2}$ gas. Pure Fe oxides were however not found in the external scale at even the

\section{(a)}

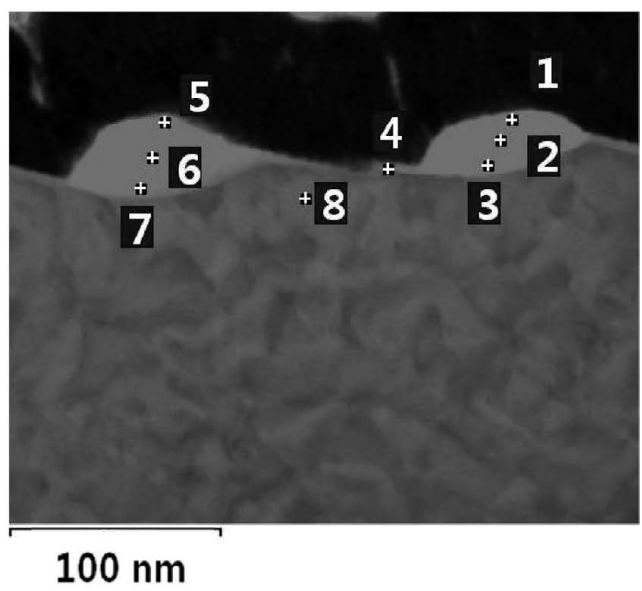

(b)

Fig. 5. Surface and cross section image of a sample annealed at $800^{\circ} \mathrm{C}$ in $\mathrm{H}_{2}-5 \% \mathrm{H}_{2}$ of D.P $-40{ }^{\circ} \mathrm{C}$. Gas flow rate is 100 $\ell /$ min. (a) a surface image by FE-SEM, (b) a cross section image by STEM and point number $1-8$ indicates EDS point analysis spots. 
highest gas flow rates investigated in this study. One of the reasons for the difference could be difference in the reaction-chamber size of the furnaces used in the studies. Kwon's experiment was carried out in a smaller chamber in comparison to in this study and consequently the residence time of the supplied gas would be quite shorter than in the present study at the same gas flow speed. The difference in $\mathrm{O}_{2}$ level in the atmosphere could influence the test results.

Figure 6(a) show GDOES data for the surface enriched elements for the sample annealed under DP $-40^{\circ} \mathrm{C}$ with a gas flow rate of $100 \mathrm{l} / \mathrm{min}$. These surface concentrated elements indicate that oxides on the steel surface. This oxide profile demonstrates a compact external oxide layer as shown in Fig. 5. Al shows that intensively concentrated on the surface. The Al concentration, however, would be influenced by DP and gas flow rates as shown in Figs. 6(b), 6(c). Figure 6(b) shows Al profiles in GDOES data for the samples annealed under DP $0^{\circ} \mathrm{C}$ to $-40^{\circ} \mathrm{C}$ with a gas flow rate of $100 \mathrm{l} / \mathrm{min}$. In $\mathrm{DP} 0^{\circ} \mathrm{C}, \mathrm{Al}$ concentrated at low level at the surface and slightly increased again inwardly until $1 \mu \mathrm{m}$ depth. This is because Al could not contribute in the formation of external oxides and $\mathrm{Al}$ formed internally. This is the same sample shown in Figs. 2 and 1(c) where internal oxidation occurred to significant depth. On the contrary, in DP -20 and $-40^{\circ} \mathrm{C}, \mathrm{Al}$ concentrated only on the external oxides and its peak is very high in comparison to $\mathrm{DP}-0^{\circ} \mathrm{C}$. Figure $6(\mathrm{c})$ show $\mathrm{Al}$ profiles in GDOES data for the samples annealed under DP $-40^{\circ} \mathrm{C}$ with gas flow rates of 5-100 $\mathrm{\ell} / \mathrm{min}$. Even in low DP of $-40^{\circ} \mathrm{C}$, Al would not form in external oxides and internal oxides developed at low gas flow rate of $5 \mathrm{l} / \mathrm{min}$. as shown in Fig. 4. In this case external oxide layer consist in relatively low $\mathrm{Si} / \mathrm{Mn}$ ratio. $\mathrm{Al}$ concentration would sharply increased in the external oxides and few internal oxides at higher gas flow rate of 30 and 100 $\ell / \mathrm{min}$. These results indicate that a compact external oxide layer did form while very few internal oxides formed. Al is sharply increased in this compact external oxides. This oxide pattern was consistently observed under the condition of low DP and high gas flow rate for the samples shown in Figs. 1(f), 1(h) and 1(i), and 6.

The spot analyses of EDS in the external oxide layer also identified that $\mathrm{Si}, \mathrm{Fe}$ and $\mathrm{Mn}$, along with $\mathrm{Al}$ in the samples formed compact external oxides. It is likely, based on previous reports in literature, that the $\mathrm{Al}$ in the surface oxide layer would form as $\mathrm{Al}_{2} \mathrm{O}_{3}$ and/or $\mathrm{MnAl}_{2} \mathrm{O}_{4}{ }^{4,7)}$ and the formation of selective oxides on industrial steels become very complex depends on the combination of chemical species and oxygen partial pressure in atmosphere. Generally, it has been reported that a more compact and higher $\mathrm{Al}_{2} \mathrm{O}_{3}$ containing surface-oxide layer forms by the increasing the aluminum content of the alloy, ${ }^{18)}$ and/or low oxygen partial pressure. ${ }^{19}$ ) June et al., recently reported that more protective Al based surface oxides could be induced by heating the sample rapidly instead of slowly. ${ }^{20)}$ The overall results in this study clearly indicate that surface oxidations in annealing are influenced also with the flow rate of the atmospheric gas.

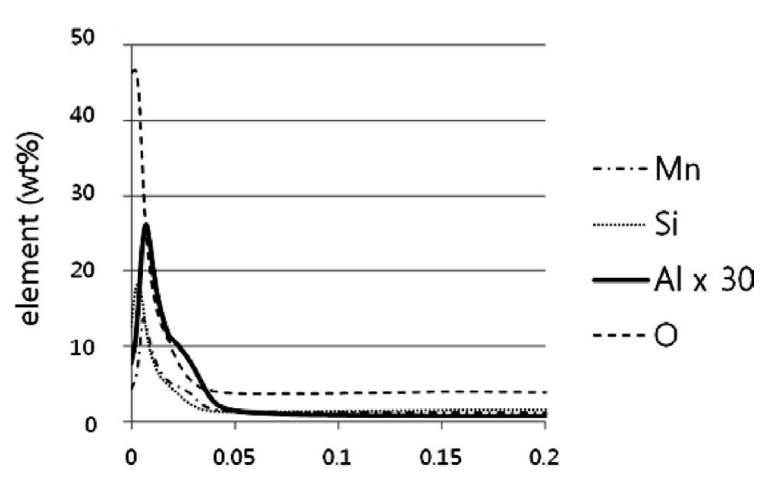

depth from surface $(\mu \mathrm{m})$

(a)

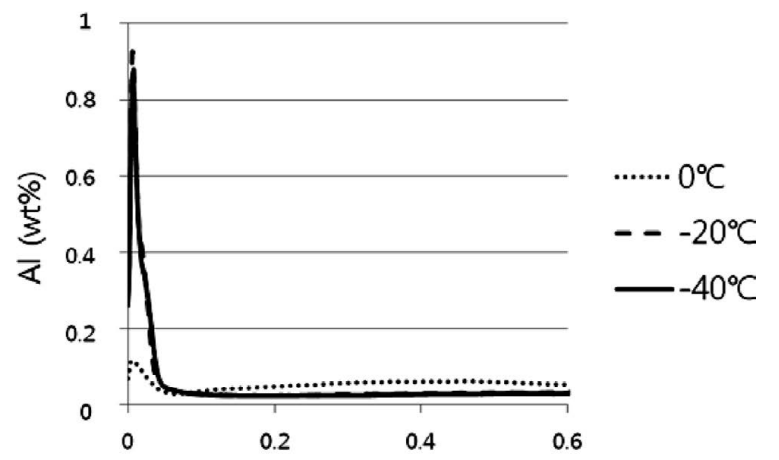

depth from surface $(\mu \mathrm{m})$

(b)

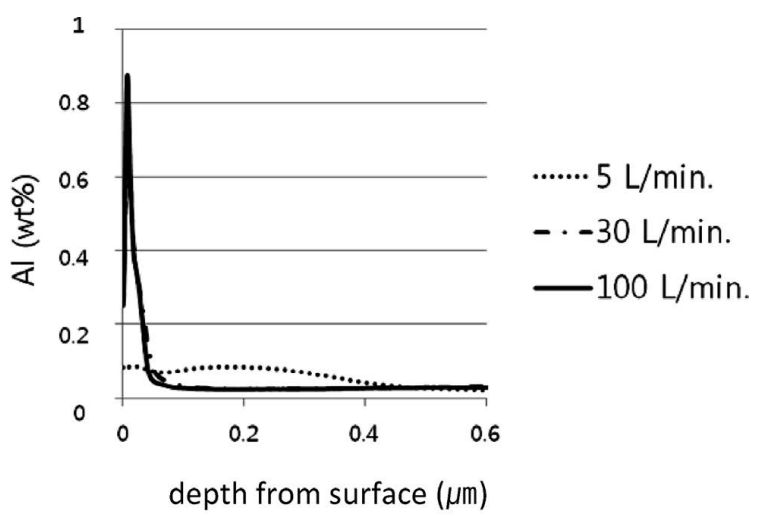

(c)

Fig. 6. GDOES Al profiles in the samples annealed at $800^{\circ} \mathrm{C}$ in $\mathrm{N}_{2}-5 \% \mathrm{H}_{2}$ of DP $0{ }^{\circ} \mathrm{C}$ and $-40^{\circ} \mathrm{C}$ with gas flow rate of 100 $\ell / \mathrm{min}$. 


\subsection{Classification for Oxidation Mode}

When the DP is lower and gas flow rate is relatively high thin external oxides form with few or no internal oxides as shown in Figs. 1(f), 1(h), 1(i) and 6. This group is henceforth referred to as "group I". Oxides exist as very thin flat oxides of several nano meters thickness and bulk like nodular oxides of $40 \mathrm{~nm}$ in thickness. They consist of pure $\mathrm{SiO}_{2}$ and $\mathrm{Si}-\mathrm{Mn}$ oxides which have high $\mathrm{Si} / \mathrm{Mn}$ ratio. As shown in the sample of Fig. 5 and Table 5, the $\mathrm{Si} / \mathrm{Mn}$ range in this group was found to be in the range of 4.8-27.5 based on EDS spot analysis. Al is a very reactive element which can potentially protect surface protection by selective external oxidation. ${ }^{14)}$ In the same sample of Fig. 5 and Table $5,2.3-5.8$ at $\% \mathrm{Al}$ was also observed in these external oxides and this is believed to contribute to a strong diffusion barrier between atmosphere and steel matrix and it is likely that this suppressed the development of internal oxides.

When DP is $-20,-40^{\circ} \mathrm{C}$ and flow rate is lowered to $5 \mathrm{l} /$ min., the external and internal oxides formed as shown in Figs. 1(d), 1(g). The external oxides were of $20 \mathrm{~nm}$ thick-

Table 5. Spot analyses by EDS on (b) in Fig. 5 (unit: atomic\%).

\begin{tabular}{cccccccc}
\hline point & $\mathrm{O}$ & $\mathrm{Al}$ & $\mathrm{Si}$ & $\mathrm{Mn}$ & $\mathrm{Fe}$ & $\mathrm{Sb}$ & $\mathrm{Si} / \mathrm{Mn}$ \\
\hline 1 & 48.0 & - & 52.0 & - & & - & - \\
2 & 49.6 & - & 49.9 & - & 0.5 & - & - \\
3 & 48.3 & 5.8 & 34.0 & 4.3 & 7.6 & - & 7.9 \\
4 & 33.4 & 5.0 & 11.9 & 8.6 & 41.1 & - & 1.4 \\
5 & 56.2 & - & 43.8 & - & - & - & - \\
6 & 52.7 & - & 44.9 & 2.44 & - & - & 18.4 \\
7 & 46.0 & 4.24 & 20.3 & 4.2 & 23.6 & 1.7 & 4.8 \\
8 & - & - & - & 2.5 & 97.5 & - & - \\
\hline
\end{tabular}

Table 6. Oxide groupings on the annealed samples at $800^{\circ} \mathrm{C}$ in $\mathrm{H}_{2}-5 \% \mathrm{H}_{2}$ with D.P $0 \sim-40^{\circ} \mathrm{C}$ and gas flow rate $5-100$ $\ell / \mathrm{min}$.

\begin{tabular}{cccc}
\hline Gas flow DP & $\begin{array}{c}5 \ell / \mathrm{min} . \\
(28.3 \mathrm{~cm} / \mathrm{min} .)\end{array}$ & $\begin{array}{c}30 \ell / \mathrm{min} . \\
(169.8 \mathrm{~cm} / \mathrm{min} .)\end{array}$ & $\begin{array}{c}100 \ell / \mathrm{min} . \\
(565.8 \mathrm{~cm} / \mathrm{min} .)\end{array}$ \\
\hline $0^{\circ} \mathrm{C}$ & III & III & III \\
$-20^{\circ} \mathrm{C}$ & II & I + III & I \\
$-40^{\circ} \mathrm{C}$ & II & I & I \\
\hline
\end{tabular}

ness and consisted of $\mathrm{Si}-\mathrm{Mn}$ oxides with $\mathrm{Si} / \mathrm{Mn}$ ratio of 0.2-3.3 and faceted nodular Mn oxides in the sample as shown in Fig. 4. There was no or little Al detected in the external oxide. The internal oxides formed as small islands or followed on grain boundaries and some oxides forms network through grain boundaries. The depth of internal oxide extended to $500 \mathrm{~nm}$ beneath the surface. It is considered that the external oxides in this case did not prevent the formation of internal oxides due to allowance of inward anion transport and/or allowing access of gas through cavities. This oxidation pattern is denoted as "group II". Figure 4 describes the characteristic features in this group.

When DP was lowered to $0^{\circ} \mathrm{C}$, internal oxides developed distinctively and increased in depth with gas flow rates as shown in Figs. 1(a), 1(b), 1(c). The external oxides were formed irregularly and were insufficient to entirely cover the steel surface. It is considered that inward diffusion of $\mathrm{O}$-anions dominated due to higher water vapor containing atmosphere, especially during the initial oxidation stage. This causes the preferable formation of internal oxides with the elements less noble than the matrix, i.e. Si, Mn, $\mathrm{Al}$ which are captured internally before they reach the steel surface and these result in a non-continuous external oxide layer. The internal oxides would grow further during the annealing because of the insufficient blocking of the inward diffusion of oxygen atoms due to the non protective external oxide layer. These oxidation pattern would be called as "group III". Figure 2 describes characteristic features in this group.

The promotion of internal oxides with DP could be explained by increasing the partial pressure of oxygen in annealing atmosphere ${ }^{21,22)}$ follows from Wagner's model ${ }^{23)}$ for selective oxidation of a reactive element in a nonreacting matrix. The presence of water vapor enhances the formation of internal oxides due to the dissolved hydrogen $\left(\mathrm{H}^{+}\right)$attacks through the external oxide layers on the surface. ${ }^{24-27)}$

The sample annealed at DP $-20^{\circ} \mathrm{C}$ in a gas flow rate of 30 $\ell /$ min. indicates as an intermediate form of group I and III.

Table 6 shows oxide pattern as indicates group I, II, III in the test conditions in this study. Figure 7 depicted oxidation models as these grouping. It shows that the gas flow rate is a very important factor for the formation of annealing oxides at lower DP conditions. Increase of gas flow rate promotes compact external oxides of $\mathrm{Al}$ and $\mathrm{Si}$. This external oxide seems to provide an effective diffusion barrier to prevent the growth of internal oxides (group I). Even at low DP when

\section{Group I \\ Group II \\ Group III}

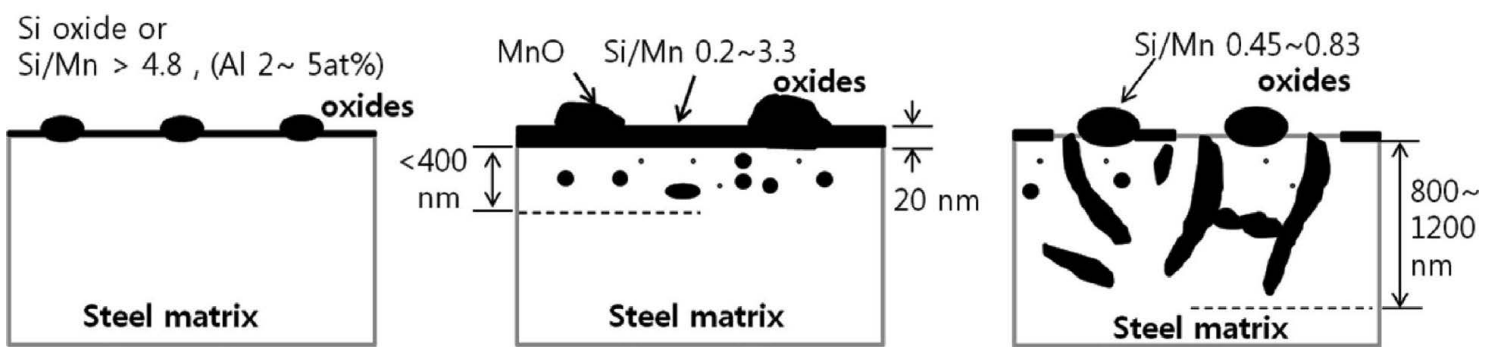

Fig. 7. Schematic oxidation models grouped as I-III in Table 5. 
the flow rate is low, external oxides do not form compact enough oxides to prevent inter diffusion during the annealing and internal oxides forms isolated forms (group II). At high DP the external oxide forms but is not sufficiently to cover the entire steel surface and in this case internal oxides greatly developed following grain boundary networks regardless of gas flow rate (group III).

Based on Table 6 and Fig. 7, the results from the current investigation can be summarized as follows: Compact $\mathrm{Al}$ containing-continuous external scales which prevent internal oxides form at sufficiently low DP and high gas-flow rates. At Higher DP and lower gas-flow rates the internal oxidation becomes more substantial and the external scale less continuous. The role of flow-rate is therefore critical, and it should be noted that gas flow rates are mostly un-regulated and un-monitored in industrial furnaces.

\subsection{Oxide Growth Through Gas Phase Diffusion}

Under conditions where the gas is lean in oxidizing molecules, the gas phase supply becomes important and the growth of oxides can be expressed through a linear rate constant, expressed ${ }^{28)}$ as

$$
\mathrm{K}_{1}=\mathrm{M}_{\mathrm{i}} \mathrm{K}_{\mathrm{MTC}}\left(\mathrm{C}_{\mathrm{i}}^{\mathrm{G}}-\mathrm{G}_{\mathrm{i}}^{*}\right)
$$

In which, $\mathrm{K}_{\mathrm{MTC}}$ is the mass-transfer coefficient $(\mathrm{cm} / \mathrm{s}) . \mathrm{M}_{\mathrm{i}}$ is the molar mass of the oxidizing gas element ( $\mathrm{g} / \mathrm{g}$-mole) and $\mathrm{C}_{\mathrm{i}}$ is the molar concentration of the oxidizing molecule in the gas mixture $\left(\right.$ moles $/ \mathrm{cm}^{3}$ ), where the superscript $\mathrm{G}$ refers to the bulk of the gas and * the sample surface. The mass-transfer coefficient $\mathrm{K}_{\mathrm{MTC}}$ can be estimated for a laminar boundary layer to a flat surface through the RanzMarshall correlation: ${ }^{28,29)}$

$$
\mathrm{k}_{\mathrm{MTC}}=\frac{4}{3} \frac{D_{i}}{1}(\mathrm{Re})^{\frac{1}{2}}(\mathrm{Sc})^{\frac{1}{3}}
$$

Here, $D_{i}$ is the binary gas diffusion coefficient of oxidizing gas element, 1 is length of the sample, Re is the dimensionless Reynolds number, Sc is the dimensionless Schmidt number. Equations (1) and (2) can be used to describe the transport of $\mathrm{O}_{2}$ and $\mathrm{H}_{2} \mathrm{O}$. The relative importance of $\mathrm{O}_{2}$ vs. $\mathrm{H}_{2} \mathrm{O}$ needs however to be considered in light of the gas phase equilibration and dissociation kinetics. From Table 2 it is clear that in the range of gas atmospheres used in this study the presence of $\mathrm{O}_{2}$ can be neglected if gas equilibration is assumed, and $\mathrm{H}_{2} \mathrm{O}$ would be the gaseous species that is responsible for oxidation. If the gas flow rate is increased, the supply of oxidizing molecules (described by Eq. (1) is increased but in addition, the likelihood of gas equilibration is decreased, due to a shorter residence time in the furnace and thus the presence of any $\mathrm{O}_{2}$ impurities due to leaks may become important.

From the Eqs. (1) and (2), the linear rate, describing the transport of oxidizing molecules to the steel surface can be calculated. The oxide growth resulting from this supply can then be estimated with the assumption that the entire surface oxidizes uniformly. ${ }^{28)}$ Table 7 shows gas access rates to the steel surface and oxide thicknesses are calculated based on a $61 \mathrm{~s}$ annealing soaking time. The data in Table 7 is limited to the 3 cases where oxidation was limited to external oxidation since it is hard to estimate the amount of internal oxides. From the GDOES element profiles, the areas of surface peaks are calculated by integration to compare the relative amount of each element on the surface of annealed samples. Si/Mn ratios in oxides from the GDOES profile integrals also listed in Table 7. Actual oxide thicknesses are estimated from the oxygen profile obtained in the GDOES analyses. Figure 8 shows STEM images for the oxide layer and $\mathrm{O}$ profiles of the GDOES for the above 3 samples. Oxide thickness determined from the surface to the depth where $10 \mathrm{wt} \%$ of $\mathrm{O}$. This is because that below $10 \mathrm{wt} \%$ of $\mathrm{O}$ is under the influence of the oxide/substrate boundaries.

In Abuluwefa's study ${ }^{28)}$ the calculated results and real oxide growth show good agreement due to the formation of homogeneous Fe oxides during a relatively long time. In this study, however, the calculation and measurements do not agree as well, especially for the case of DP $-20^{\circ} \mathrm{C}$ with $100 \mathrm{l} / \mathrm{min}$. gas flow. This is because the different of external oxides as diffusion barrier between two studies. In this study, higher $\mathrm{SiO}_{2}$ ratio in the external oxide layer leading to suppression of ionic diffusion and thereby causing the oxide growth which not to be solely controlled by gas phase transport. Similarly, at DP $-40^{\circ} \mathrm{C}$, the higher gas flow rate (100 l/min.) brings more oxidizing gas on the steel surface but less oxide is than at the lower gas flow rate $(30 \mathrm{l} / \mathrm{min}$.). The higher $\mathrm{Si} / \mathrm{Mn}$ ratio, at the higher flow rate, could be suppressing the oxide growth.

\subsection{Non Equilibrium Oxidation in Annealing}

It is clearly shown in this study that higher gas flow rate could induce the formation of the compact oxide layer such as $\mathrm{SiO}_{2}$ and $\mathrm{Al}_{2} \mathrm{O}_{3}$ more efficiently. In the flowing gas, gas equilibrium could be attained by gas flow rates due to the equilibrium would be the function of gas diffusion and specific gas reaction rate in the atmosphere. Grabke et $a l .{ }^{13)}$ showed the oxide-carbide reaction in flowing nonequilibrium mixture gases at elevated temperature, which

Table 7. Gas diffusion rate to the steel surface and external oxide thickness both by calculation and measurement in the test samples.

\begin{tabular}{cccc}
\hline & $\mathrm{DP}-20^{\circ} \mathrm{C} / 100 \ell / \mathrm{min}$. & $\mathrm{DP}-40^{\circ} \mathrm{C} / 30 \ell / \mathrm{min}$. & $\mathrm{DP}-40^{\circ} \mathrm{C} / 100 \ell / \mathrm{min}$. \\
\hline $\begin{array}{c}\text { Linear rate of } \mathrm{H}_{2} \mathrm{O}(\mathrm{g}) \text { access to the } \\
\text { steel surface } / \mathrm{mole}^{2} / \mathrm{cm}^{2}-\mathrm{s}\end{array}$ & $3.03 \times 10^{-8}$ & $2.05 \times 10^{-9}$ & $3.83 \times 10^{-9}$ \\
Thickness (calculated) $/ \mathrm{nm}$ & 216 & 15 & 27 \\
Thickness (measured) $/ \mathrm{nm}$ & 17 & 23 & 20 \\
$\mathrm{Si} /$ Mn ratio in external oxide & 1.16 & 0.7 & 0.92 \\
\hline
\end{tabular}


DP $-20^{\circ} \mathrm{C}, 100 \mathrm{l} / \mathrm{min}$

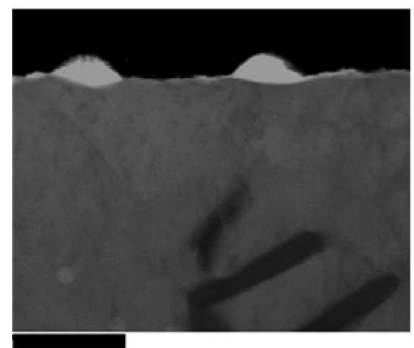

$100 \mu \mathrm{m}$
DP $-40^{\circ} \mathrm{C}, 30 \ell / \mathrm{min}$

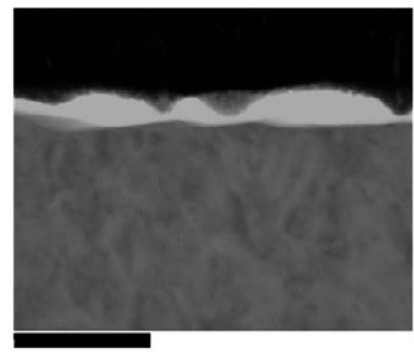

$100 \mu \mathrm{m}$
DP $-40^{\circ} \mathrm{C}, 100 \mathrm{l} / \mathrm{min}$

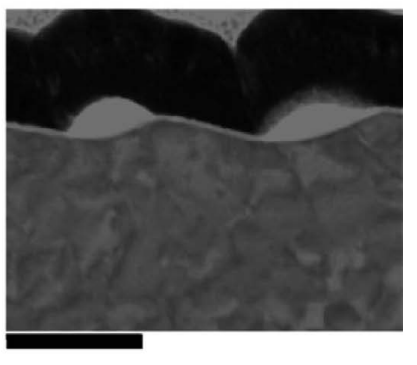

$100 \mu \mathrm{m}$

(a)

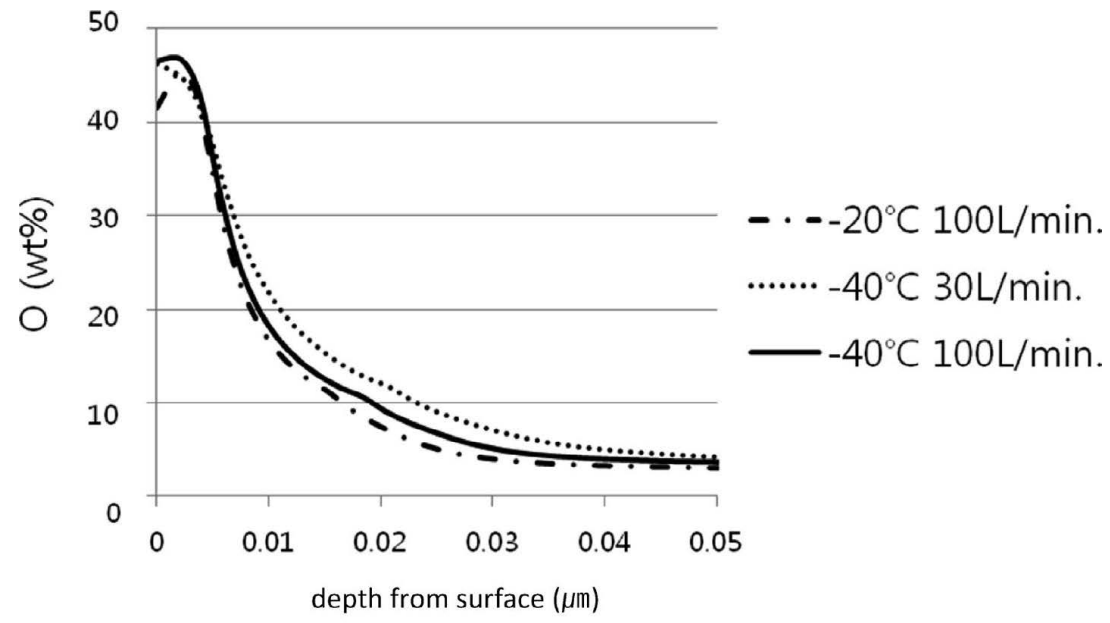

(b)

Fig. 8. External oxides formed on the specimens at DP -20 and $-40^{\circ} \mathrm{C}$ with gas flow rate of 30 and $100 \mathrm{l} / \mathrm{min}$. (a) STEM cross section images, (b) GDOES profiles for $\mathrm{O}$ on the specimens.

demonstrate that the gas reaction rates depends on gas concentration and gas flow rate. This indicates that gas reactions have their own equilibrium time and oxidation proceeds under non-equilibrium state when gas flow rate is too excessive to reach the gas equilibrium.

During equilibrium gas condition, gas flow rate would not appreciably influence the selective oxidation of $\mathrm{Si}$ or Al. However, in this study, gas is supplied from room temperature and the gas reaction occurred during heated up in the furnace. It is considered that when the gas flow-rate is increased, the gas phase may not attain equilibrium due to short residence time of supply gas in annealing furnace. In this case the quantity of $\mathrm{O}_{2}$ impurities could affect the formation of initial selective oxidation of $\mathrm{Si}$ and $\mathrm{Al}$ and thereby control the formation of external oxides. The formation of external oxides could determine the promotion of internal oxides and entire oxide growth as shown in Group I-III in Fig. 7.

Free oxygen may react with the surface differently to water vapor. From Table 6 it can be seen that high gas-flow rates promotes Group I oxides, i.e. a continuous external layer with little/no internal precipitates.

If the free oxygen in the gas due to leaks and impurities are not equilibrated before reaching the metal surface, this may oxidize any elements it can on the surface. When the flow rate is too excessive to allow for equilibration, then any available oxygen could form Fe oxides as reported by Kwon et al. $^{12)}$ Since the system is not in equilibrium, the surface oxide, would eventually get reduced but reduction may be kinetically slow and therefore not proceed to completion. On the other hand, if the gas flow rate for the same gas composition is lowered and any non-equilibrium oxygen is given time to react with hydrogen to establish the equilibrium oxygen partial pressure, then there will be less/ no Fe-oxides formed in the first place. Kwon et al. ${ }^{12)}$ showed this by comparing the difference in surface oxides formed at high flow rates with low flow rates and by using a catalyst to force equilibration to occur.

In this study, it is discussed about the assumed possible reactions in non equilibrium gas atmosphere with various gas flow rates. Experimental result suggests that the oxidation concept in the non equilibrium gas reaction should be considered to the understanding of the complex oxidation phenomena in the furnace annealing. However, in order to quantify the non-equilibrium oxidation during annealing process it needs further study to measure in-situ $\mathrm{Po}_{2}$ during reaction and gas reaction rates at elevated temperature.

Oxide morphologies and its compositions could influence the $\mathrm{Zn}$ wettability during hot dipping due to the oxide impeding the formation of inhibition layer. There has been many trials to control the oxide formation such as pre-oxidation $^{30,31)}$ or by increasing DP during annealing ${ }^{32}$ ) in order to promoting $\mathrm{Zn}$ wettability. However, the non equilibrium gas state and the oxidation during heating have been disregarded. Further study for gas diffusion and the behavior in non equilibrium state is needed to understand 
the complexity of the transient kinetic processes in industrial annealing furnaces.

\section{Conclusion}

Steels composed of $0.09 \mathrm{C}-1.7 \mathrm{Mn}-1.22 \mathrm{Si}-0.02 \mathrm{Sb}-0.044 \mathrm{Al}-$ $0.0004 \mathrm{~B}\left(\mathrm{wt} \%\right.$ ) were annealed in $\mathrm{N}_{2}-5 \% \mathrm{H}_{2}$ at $800^{\circ} \mathrm{C}$. The resulting oxidation products were documented based on variations in dew point and gas flow rates. The examined dew point range was $0 \sim 40^{\circ} \mathrm{C}$ and gas flow rates between 5-100 $\ell / \mathrm{min}$. were used. The pertinent findings were as follows.

(1) The growth of internal oxides was found to be closely related with the physical \& chemical properties of external oxides. At low DP and fast gas flow rate, $\mathrm{DP}-40^{\circ} \mathrm{C}$ with flow rate $30,100 \mathrm{\ell} / \mathrm{min}$. and $\mathrm{DP}-40^{\circ} \mathrm{C}$ with flow rate 100 l/min., compact $\mathrm{SiO}_{2}$ rich external oxide layers formed on the steel surface and suppressed the growth of internal oxides. Al oxides were concentrated in the external oxide layers.

(2) At DP $0^{\circ} \mathrm{C}$, internal oxides formed and extended deeply into the alloy and followed the grain boundary network in the matrix. This happened at all the gas flow rates investigated and the depth of internal oxide increases with increasing gas flow rate.

(3) In the remaining experimental conditions (other than those in (1), (2)), $\mathrm{Si}-\mathrm{Mn}$ oxides ( $\mathrm{Si} / \mathrm{Mn}$ ratio 0.2-3.3) formed on the surface of thickness about $20 \mathrm{~nm}$ and isolated internal oxides formed in the underlying alloy at both grain boundaries and grain interiors.

\section{REFERENCES}

1) D. K. Matlock and J. G. Speer: Microstructure and Texture in Steels and other materials, Springer, New York, (2009), 185.

2) H. Karbasian and A. E. Tekkaya: J. Mater. Process Technol., 210 (2010), 2103

3) I. Hertveldt, B. C. De Cooman and S. Claessens: Metall. Mater.
Trans. A, 31 (2000), 1227.

4) E. M. Bellhouse and J. R. McDermid: Proc. Materials Science \& Technology Zinc-Coated Steel Sheet, MS\&T'09, Pittsburgh, (2009), 913.

5) I. Cvijovic, I. Parezanovic and M. Spiegel: Corros. Sci., 48 (2006), 980.

6) Z. T. Zhang, I. R. Sohn, F. S. Pettit, G. H. Meier and S. Sridhar: Metall. Mater. Trans. B, 40 (2009), 550.

7) Y. F. Gong, H. S. Kim and B. C. De Cooman: ISIJ Int., 49 (2009), 557.

8) I. R. Sohn: Corros. Sci. Technol., 9 (2010), 259

9) F. Li, H. Liu, W. Shi and L. Li: J. Coat. Technol. Res., 8 (2011), 639.

10) A. Ollivier-Leduc, M. L. Giorgi, D. Balloy and J. B. Guillot: Corros. Sci., 53 (2011), 1375.

11) V. Linsa, L. Madeira, J. Vilela, M. Andrade, V. Buono, J. Guimaraes and E. Alvarenga: Appl. Surf. Sci., 257 (2011), 5871.

12) Y. Kwon and S. Sridhar: Corros. Sci. Tech., 10 (2011), 189.

13) H. J. Grabke, P. C. Prasannan and E. M. Muller: Metall. Trans. A, 17 (1986), 915.

14) C. W. Bale, P. Chartrand, S. A. Decterov, G. Eriksson, K. Hack, R. B. Mahfoud, J. Melançon, A. D. Pelton and S. Petersen: Calphad, 62 (2002), 189.

15) Y. Suzuki and K. Kyono: Testu-to-Hagané, 89 (2003), 66.

16) N. Birsk, G. Meier and F. Pettit: Introduction to the HighTemperature Oxidation of Metals, 2nd. ed., Cambridge University Press, New York, (2006), 101

17) E. Sampson and S. Sridhar: Metall. Trans. B, 44 (2013), 1124.

18) D. Pilone: Recent Pat Mater. Sci., 2 (2009), 27.

19) S. H. Hong, Y. Zhu, K. Mimura and M. Isshiki: Corros. Sci., 48 (2006), 3692.

20) J. Bott, H. Yin and S. Sridhar: Mater. Trans. B, 45 (2014), 2222

21) S. Swaminathan, M. Rohwerder and M. Spiegel: Surf. Coat. Tech., 205 (2011), 4089.

22) D. Huin, P. Flauder and J.-B. Leblond : Oxid. Met., 64 (2005), 131.

23) C. Wagner: Z. Elektrochem., 63 (1959), 772.

24) C. T. Fujii and R. A. Meussner: J. Electrochem. Soc., 111 (1964), 1215.

25) S. Hayashi, M. Fukumoto, S. Maeda and T. Narita: Zairyo-toKankyo, 51 (2002), 115.

26) Y. Murata, K. Nagai, M. Nakai, T. Kunieda and M. Morinaga: J. Jpn. Inst. Met., 71 (2007), 68

27) W. J. Quadakkers, J. Zurek and M. Hansel: JOM, 61 (2009), 44.

28) H. Abuluwefa, R. I. L. Guthrie and F. Ajerscht: Oxid. Met., 46 (1996), 423.

29) E. Sampson: Doctoral Thesis, Carnegie Mellon Univ., Pittsburgh, (2013).

30) Y. Suzuki, Y. Sugimoto and S. Fujita: Proc. Galvatech 2007 Conf., Galvatech, Osaka, (2007), 433.

31) M. Nordon, M. Blumenau and R. Schonenberg: Iron Steel Tech., 2 (2013), 67.

32) L. Bordignon and X. Eynde: Proc. Galvatech 2007 Conf., Galvatech, Osaka, (2007), 454. 